\title{
Contrabando de afectos, fugas de capitales y otros desplazamientos. Relaciones de sexo comercial más allá de las fronteras de la prostitución*
}

\author{
Santiago Morcillo**
}

\section{Resumen}

Este artículo aborda los vínculos entre mujeres que ofrecen sexo comercial y sus clientes, enfocando en aquellas relaciones que se cargan de afectos y escapan a los estereotipos de la prostitución. A partir del análisis de entrevistas con mujeres que hacen sexo comercial bajo diferentes modalidades y en tres ciudades de Argentina, se delinean tres tipos de relaciones con diversas formas de arreglos económicos y sexo-afectivos. Desde allí se abre la reflexión sobre los posibles sentidos de los intercambios de sexo comercial más allá de los esquemas dicotómicos.

Palabras clave: Sexo Comercial, Afecto, Dinero, Clientes.

" Recibido para publicación el 04 de junio de 2014, aceptado el 18 de octubre de 2016.

** Doctor en Ciencias Sociales por la Universidad de Buenos Aires, investigador de CONICET - UNSJ - IISE, Buenos Aires, Argentina. santiagomorcillo@gmail.com 
Smuggling Affections, Capital Flights and Other Displacements.

Relationships of Commercial Sex Beyond the Borders of Prostitution

\begin{abstract}
This article discusses the bonds between women who perform commercial sex and their clients focusing on relationships where the affective ties moves beyond stereotypes of prostitution. Based on the analysis of interviews conducted with women in different settings of commercial sex in three cities of Argentina, I outline three types of relationships with diverse forms of economic and sex-affective exchanges. This alows to reflect on the possible meanings for commercial sex trade beyond dichotomous schemes.
\end{abstract}

Keywords: Commercial Sex, Affection, Money, Customers. 


\title{
Introducción
}

\author{
"El capital confunde todo: \\ libidiniza los dineros, \\ monetariza las pasiones" \\ Néstor Perlongher
}

El ideario romántico pretende construir los vínculos amorosos como un espacio aislado del mundo social donde desaparecería el interés económico (Giddens, 1998; Illouz, 2006), justamente contra esta imagen que se recorta el mundo abyecto de la prostitución donde el dinero absorbe todos los sentidos y signa la degradación simbólica del sexo. En este marco cultural estigmatizante, varios estudios antropológicos y sociológicos han descripto cómo las mujeres que hacen sexo comercial buscan construir una frontera de múltiples dimensiones (simbólica, corporal, espacio-temporal y relacional) como intento de segregar el sexo comercial de la vida personal (Allen et al., 2003; Araújo, 2006; Brewis; Linstead, 2000; Fonseca, 1996; Freitas, 1985; Gaspar, 1985; Kong, 2006; Morcillo, 2011; Pasini, 2000; Sanders, 2002, 2005). Esta frontera responde a la necesidad tanto de manejar la identidad estigmatizada asociada a la prostitución como de llevar a cabo el trabajo emocional y las performances sexuales implicadas en los encuentros con los clientes. Como parte de estos esfuerzos, las mujeres que hacen sexo comercial plantean una marcada división en los vínculos que entablan con los hombres. En primera instancia, todas las mujeres que entrevisté y con quienes conversé durante el trabajo de campo señalaban que distinguían entre los clientes (esfera comercial-laboral) y otros vínculos (esfera afectivapersonal), y esta distinción aparecía como una regla primordial.

Sin embargo, luego también pude conocer las formas de permeabilidad y zonas grises entre categorías donde se abría un conjunto de sentidos que desdibujaban las identidades y las prácticas consideradas típicas de la prostitución. La narrativa dominante (potenciada en el contexto actual de "lucha contra la trata de personas") que homogeneiza las relaciones prostitutacliente únicamente en torno a la violencia de género (Barry, 1988; 
Dworkin, 1993; Jeffreys, 2009; MacKinnon, 1993, 2001), descuida los aspectos afectivos de las relaciones en el mercado sexual que han recibido relativamente poca atención desde las ciencias sociales, tal como señalaba Laura Agustín en su artículo Lo no hablado (2004). Solo recientemente, de la mano de las investigaciones sobre turismo sexual, se ha comenzado a indagar más en esta perspectiva. Por ejemplo, en los trabajos de Adriana Piscitelli $(2007,2008,2011)$ y de un conjunto de investigadoras/es que han abordado las cuestiones relativas a los sentimientos en los mercados sexuales trasnacionales, asociados al turismo sexual o las migraciones (Cabezas, 2004; Piscitelli; Oliveira Assis; Olivar, 2011).

En este artículo analizo los tránsitos y las categorías intersticiales que emergen entre las relaciones comerciales y las relaciones afectivas o de pareja. Para ello describo los vínculos que se encuentran en puntos intermedios respecto de la división dicotómica (comercio / afecto-amor) y suponen desplazamientos de las relaciones estereotípicas de prostitución cargadas de estigma y degradación simbólica. Estos corrimientos se expresan tanto en el plano de los afectos como en los intercambios monetarios o de bienes y los sentidos que estos encierran, por ello sostengo que permiten abrir interrogantes analíticos $y$ resignificar las experiencias e identificaciones que las mujeres asocian con el sexo comercial. Las experiencias de enamoramientos, o las figuras limítrofes del cliente-amigo y el amante-renta, permiten comprender cómo la maleabilidad de los vínculos los lleva más allá del esquema binario que parece plantearse en un primer momento.

Las distinciones tajantes entre las relaciones personales y aquellas de sexo comercial pueden ser vistas de una forma más fluida si consideramos algunos tipos de vínculos que son intersticiales o de tránsito. Estos vínculos con clientes, que adquieren una carga afectiva y/o amorosa, se ubican en el margen que, sin ser una relación de pareja, excede el marco del estereotipo de prostitución. Como veremos, aquí la circulación de bienes va más allá de lo monetario y de la lógica comercial. En este sentido será importante recordar que "en la economía sexual, 
encontramos que los pagos pueden funcionar para crear $y$ mantener distinciones que importan moral, sentimental $y$ personalmente" (Zelizer, 2008:13). Para analizar los sentidos que adquieren los diversos pagos recupero críticamente la distinción entre compensaciones, derechos y regalos ${ }^{1}$ que plantea Viviana Zelizer (2008), pero además considero el papel de los intercambios no monetarios, tomando en cuenta algunas especificidades de los vínculos en el sexo comercial.

Siguiendo lo planteado por Paola Tabet (2004), podemos concebir un abanico de relaciones económico-sexuales que se expresan, además de por las formas de pago, por lo estricto o no del tiempo del encuentro con los clientes y por el tipo de servicios $e$ involucramiento emocional. En este artículo planteo que, si consideramos el papel que juegan estas variables, veremos que hay un espacio indefinido de intersecciones entre vínculos que son afectivos o amorosos y aquellos que sólo implicarían la búsqueda rédito económico. Las mujeres que hacen sexo comercial pueden esforzarse por mantener estos mundos separados - tal como indican Zelizer $^{2}$ y varios de los trabajos citados al comienzo. Sin

1 Zelizer plantea que hay "tres maneras posibles de organizar cualquier tipo de pago monetario: como compensación (intercambio directo), como derecho (el derecho a una participación) y como regalo (el otorgamiento voluntario de una persona a otra). El dinero como compensación implica un intercambio equitativo de valores y una cierta distancia, contingencia, negociación y control entre las partes. El dinero como derecho implica fuertes reclamos de poder y autonomía por parte del receptor. El dinero como regalo implica subordinación y arbitrariedad. Las tres formas de pago definen la calidad de las relaciones sociales entre las partes. En total, derechos y regalos implican una relación social más durable entre ellas que lo que supone la compensación. La gente se preocupa mucho por hacer esas distinciones; la transferencia (monetaria) incorrecta desafía, confunde o viola la definición de las relaciones sociales particulares" (Zelizer, 2008:44, énfasis añadido)

2 Es lo que Zelizer (2009a, 2009b) llama la teoría de las "esferas separadas" y su correlativa de "mundos hostiles" para referirse a la ideología que sostiene la separación entre intimidad y mundo económico como un fundamento moral. La autora se esfuerza por mostrar esto como una simplificación pues los medios por lo que se expresan los significados de las relaciones, incluyendo las íntimas, pueden ser también económicos, e incluso monetarios. 
embargo, un análisis más detallado mostrará que el énfasis puesto y los modos de sostener esta frontera pueden variar, y el paso del tiempo puede ir transformando el sentido de los vínculos. Los intercambios de dinero, regalos, sexo y afecto pueden desencajar las relaciones y situarlas más allá o más acá de la dicotomía cliente/pareja.

A fin de conocer y analizar diversas experiencias respecto de los vínculos con los clientes he abordado distintos escenarios de sexo comercial. El trabajo de campo incluyó tres ciudades con características disímiles ${ }^{3}$ - Buenos Aires, Rosario y San Juan - y distintas modalidades o estratos de prostitución: de calle (CLL), en "privados" (PV) o cabarets (CB), y "escorts" (ES) que fueron contactadas telefónicamente $e^{4}$. La muestra de conveniencia quedó conformada por 35 mujeres entrevistadas, cuyas edades iban desde los 21 a los 52 años. Las entrevistas semi-estructuradas fueron complementadas con la observación y además sostuve reiteradas charlas informales cara a cara. También realicé trece entrevistas semi-estructuradas a travestis. Estas entrevistas no formaron parte del análisis central, pero han servido de contraste para comprender mejor las experiencias de las mujeres. Asimismo, en una fase exploratoria realicé algunas entrevistas a clientes regulares de sexo comercial.

3 Estas incluyen, desde un plano más general, diferencias en lo económico, sociocultural y la moral sexual, y a nivel más puntual los procesos de constitución histórica del sector del sexo comercial y de las organizaciones que nuclean a las personas que realizan sexo dicha actividad.

${ }^{4}$ Los que se conocen como "privados" son departamentos o pequeñas casas generalmente regenteadas por proxenetas. según las entrevistadas, esta es la modalidad que registra la mayor cuota de explotación. "Escort" es la denominación nativa que hace referencia al nivel más "exclusivo" expresado en las tarifas más altas. Además, esta modalidad/estrato, junto con la de calle, era donde las mujeres decían contar con mayor independencia para administrar sus ingresos. 
A partir de los relatos de las entrevistadas he organizado en tres tipos ${ }^{5}$ las relaciones que implican alteraciones respecto del esquema dicotómico comercio / intimidad: los casos de clientes en su tránsito hacia ser (intentos de) parejas amorosas; los clientesamigos como categoría intersticial más estabilizada que expresa afectos, pero mantiene el pago por "salida" y suma otras formas de intercambios; y los amantes-renta o "viejos" como relaciones sin pagos tarifados y que suelen suponer una pretensión de un vínculo exclusivo.

\section{Tránsitos entre la remuneración y la gratuidad}

Fernanda me contó que tuvo varios encuentros y un par de "charlas de café" con un cliente donde se conocieron "como amigos" y la relación fue mutando. La redefinición del vínculo fue ajustando algunos parámetros:

Hasta que tuvo la confianza de llevarme a su casa... Entonces ya me daba vergüenza decirle "me debes tanto". Cuando me llevó a su casa. Ya ahí como yo intuía... Bueno, pero me quedaba la duda igual... y después de que me fui me quedé pensando en eso, pero cuando lo volví a ver le dije: "Mirá que... cuando me llevaste a tu casa, estuvimos juntos... y no me diste ni las gracias". "No -me dijo- porque yo ya no quiero... Yo te puedo dar una ayuda como quien dice... qué sé yo, comprarte un regalo, comprarte esto, pero no... no así, porque yo ya no te quiero asî". Entonces le digo: "Bueno, pero dime cómo me quieres, porque la verdad que no entiendo" (Risa). ¿No? y ahí que se había enamorado (Fernanda, 37 años, CB).

Aquí aparecen dos puntos que resultan significativos para percibir la transformación del vínculo: entrar en la casa del cliente y dejar de cobrar. En las experiencias de varias de las

5 Estos tipos no son excluyentes - pues a veces podían mezclarse -, ni exhaustivos respecto de las posibles fugas de la dicotomía, pero representan los casos más mencionados. 
entrevistadas entrar en la casa de un cliente - o que él entre en la de ellas - significaba una apertura de la vida privada. Este papel de la entrada en la casa puede entenderse en relación con la oposición estructurante que separa casa/calle, o casa/trabajo, tanto como ligado a la concepción de la cohabitación como un indicador de una relación de pareja. El otro punto, que marca una diferencia más importante aún, es dejar de cobrar, o que deje de haber una remuneración explícita por cada encuentro sexual, es decir abandonar la forma tarifada de compensación monetaria. En la descripción que hacía Fernanda, dejar de cobrar la "salida" aparece como un evento no planificado. También otras entrevistadas relataron que "en un momento sin pensarlo ya no le cobraba más" y esto significaba "crear una relación afectiva. O sea, a partir de que... ya no era mi trabajo, no era porque yo no estaba fingiendo algo". Aquí esa acción no calculada, "sin pensarlo", parece ser señal del desinterés romántico. Por el contrario cobrar una tarifa fija aparecía como un intento por "no mezclar el placer con el trabajo", una regla muy clara para la mayoría de las entrevistadas. Cobrar por la "salida" funciona como signo que enmarca el vínculo y le da sentidos que las entrevistadas oponen al amor (entendido como amor romántico). Dejar de cobrar resulta ser un indicador de que el vínculo comercial ha dado lugar a otro tipo de lazo.

Sea un gesto irreflexivo o conscientemente motivado por los sentimientos amorosos, dejar de cobrar es una señal de que se han alterado los parámetros del intercambio sexual económico y un indicio de que puede haber otro tipo de vínculo. No siempre está claro que el horizonte cierto de este vínculo naciente sea el de una pareja estable pues esto encierra un conjunto de complejidades para las mujeres que hacen sexo comercial ${ }^{6}$. Pero sí

6 Según las entrevistadas, las relaciones de pareja son complicadas o directamente incompatibles para quienes hacen sexo comercial. Los obstáculos emergían en: el terreno emocional, por las dificultades de manejar los celos o inseguridades que generaría en la pareja (que se incrementaban cuando este era un ex cliente); en lo corporal-sexual, por el desgaste y la complejidad de estar dando constantemente diferentes significados a las prácticas sexuales (como un 
es evidente que dejar de cobrar significa una transformación de la relación esta forma de concebir las relaciones y los procesos aparecía más segmentada en las entrevistas con mujeres. Entre las travestis era frecuente la figura del "garrón"7 como forma de entablar relaciones con algunos varones. A diferencia de las parejas, estos vínculos podían ser múltiples -se pueden tener varios "garrones"-, incluir distintos grados de afecto, intimidad y una dosis importante de placer sexual. En estos casos, las travestis decían que podían sostener encuentros sexuales gratuitos sin que ello implique la necesidad o el deseo de formar una pareja estable. Esta posibilidad no fue mencionada por ninguna de las mujeres, desde sus concepciones un vínculo de este tipo entrañaría una mayor desprotección frente al estigma de "puta" y/o sería poco "profesional".

Yo ni siquiera eso sé concebir, ni un garrón, porque estoy tan estructurada que vos, yo me encamo y me tenés que pagar ¿Me entendés? Para mí siempre es un trabajo, yo digo el garrón lo voy a buscar a otro lado, no acá. ¿Me entendés? Tengo como una... no sé, tengo mi manera de trabajar así, viste, de... nada, que uno ya está. Sí aprecio, me gusta y viste nos echamos los polvos ¿Me entendés?

Pero la guita me la da (Doris, CLL, 52 años).

Varias entrevistadas estaban constantemente alerta de las estrategias de algunos clientes que buscaban obtener servicios gratuitos. En ese contexto, dejar de cobrar aparece como una trasgresión de las reglas de oficio - mayor incluso que la de compartir otros aspectos íntimos - que sólo puede ser

"servicio" o como expresión de afecto); y en lo económico, por el riesgo de abandonar el trabajo y perder la independencia o terminar manteniendo a un "fiolo" (proxeneta).

7 En el lunfardo argentino común "garrón" puede referir a un evento negativo, pero también "garronear" es pedir algo sin dar nada a cambio. Luego, en la jerga más específica del sexo comercial se denomina garrones a aquellos clientes con los que se entabla un vínculo sostenido, que incluyen lazos afectivos $e$ intercambios sexuales no remunerados. 
comprendida como símbolo del enamoramiento y el subsecuente intento de entablar una relación de pareja. Tras la confusión del enamoramiento, como una fuerza arrolladora, la concepción romántica primaba y el intento de formar una pareja buscaba reestablecer las fronteras.

Enamorarse de un cliente era frecuentemente visto como un "error de juventud", una falta de experiencia. Podía haber aprecio hacia algunos clientes, como señala Doris, pero el pago no desaparece. Entonces ¿́cómo se conciben estos vínculos donde emerge un lazo afectivo? Si bien entre las mujeres no se mencionaban los "garrones", encontré con mayor frecuencia la figura del "amigo".

Varias investigaciones sobre mercado sexual han mostrado el uso más o menos habitual de la categoría "amigos" que puede variar según los contextos (ver por ejemplo el artículo de Suzana Maia en Piscitelli et al., 2011). Si bien las entrevistadas los llamaban directamente "amigos", me referiré a estos como clientes-amigos para marcar el doble rol de este vínculo. Esto también permite diferenciarlos de los amigos que son "sólo amigos", es decir, que nunca fueron clientes. Con ellos, conocerse previamente en otro contexto y haber compartido otro tipo de intimidad inhibía la relación de sexo comercial. Además, este límite es mantenido con mayor vigor pues estas amistades son muy valoradas (especialmente cuando no hay secretos) e iniciar intercambios sexo-económicos con quienes son "sólo amigos" pondría en riesgo la estabilidad del vínculo, según las entrevistadas. Allí donde los "sólo amigos" indican la persistencia de una frontera entre vida privada y sexo comercial, los vínculos con clientes-amigos montaban sus tráficos.

\section{Cuentas claras... La extraña convivencia de amistad y dinero}

Con los clientes-amigos el trato iba más allá de las transacciones del sexo comercial e incluía "ayudas" de diverso tipo y compartir "charlas de amigos". En este tipo de vínculos, con una carga afectiva forjada a lo largo del tiempo, no se suspenden 
los pagos por las "salidas" ni las relaciones sexuales, pero se excede lo estrictamente comercial.

S: ¿De qué cosas conversan?

Daniela: Y... por ejemplo de las familias de ellos o de... del trabajo... Igual ellos saben de dónde yo soy, de lo que trabajo, de dónde vivo... Ellos me conocen la casa. Mentiras no hay... (Daniela, 26 años, PV)

Tengo, dos o tres clientes que...somos muy, muy amigos. Ya te digo, ellos vienen y si yo estoy ocupada se van a la cocina, se sirven algo, abren la heladera como si estuvieran en su casa, cosa que a mí también me agrada porque sé que están cómodos. No lo puedo hacer con todo el mundo, pero estaría bueno poder hacerlo con todo el mundo, que todo el mundo se sienta cómodos, que esa es la idea, ¿no? (Carina, 46 años, ES).

Además del afecto y la confianza, ambas entrevistadas hacen referencia a sus casas. Compartir mates, la cocina o alguna comida como contaba Carina - quien trabajaba en su departamento -, o como Luli, que ofrecía a algunos una "promo"8 y les cocinaba pizzas caseras, constituyen rasgos de domesticidad. Este punto también es significativo en el análisis de Paola Tabet (2004) quien, a partir de un conjunto de etnografías realizadas en distintos pueblos africanos, reconstruye un abanico de intercambios económicos-sexuales que complejizan la dicotomía prostitución / matrimonio. Para Tabet, el trabajo doméstico y la cohabitación hacen variar los tipos de vínculos, ampliando las categorías de conyugalidad. También los testimonios en Argentina aluden a vínculos similares, por ejemplo cuando las casas de algunos clientes estudiantes universitarios servían de refugio a las prostitutas (durante la dictadura de los 70'), compartían el techo y las comidas (ver Das Biaggio et al., 2008).

8 Diminutivo de "promoción", que se refiere a una oferta especial por un tiempo limitado. 
En el análisis de las relaciones que conjugan esferas económica y de intimidad, Zelizer considera las dimensiones de duración y amplitud de la intimidad para distinguir lo que llama "buenas combinaciones", es decir aquellas donde los/as participantes pueden evitar las confusiones y mantener ciertos acuerdos sobre la índole del vínculo. Así plantea que cuando la intimidad compartida es limitada y durante un período corto llamamos a ese vínculo "trabajo sexual" y cuando es amplia y de larga duración tendemos a llamarla unidad doméstica (Zelizer, 2009a:144). Sin embargo, los vínculos con los clientes-amigos, tanto por su duración como por los aspectos de domesticidad -o compartir espacios de comensalidad, en cenas por ejemplomuestran cómo se eluden las habituales fronteras que separan los mundos. Estos "amigos" que mencionaban las entrevistadas, no dejan de ser clientes, pero a la vez son más que simples clientes. Con afecto, un trato personal, rasgos de domesticidad y tiempos más flexibles para los encuentros, pero sin eliminar el cobro bajo la forma compensatoria, se alejan de los polos dicotómicos del matrimonio y la "prostitución" - en su imagen más estereotípica.

No es solamente un rato de diversión, es como que me siento alguien importante porque acuden a mí... más allá de lo que yo sea o para lo que labure..., para conseguir... alguien con quién hablar, una amiga... (Luli, 25 años, ES).

Las relaciones con clientes-amigos son muy apreciadas pues, aun sin producir una desidentificación como prostituta, permiten revalorizar la propia posición subjetiva en el sexo comercial compartiendo sus intimidades. Las frecuentes "charlas de amigos" permiten que los clientes-amigos conozcan aspectos personales de las mujeres (por ejemplo, muchas veces dejan de usar el "nombre artístico"). Esta mezcla de trabajo y afecto podría ser vista como una falta a las reglas del oficio. Varias investigaciones señalan que las trabajadoras sexuales crean un personaje para los clientes y se cuidan de no comentarles su intimidad, pues esta es una forma de segregar y proteger su vida 
privada (ver por ejemplo Sanders, 2005). Pude escuchar posiciones similares entre mis entrevistadas, en general refiriéndose a clientes nuevos u ocasionales.

Algo parecido sucedía con los límites que las entrevistadas decían poner sobre las prácticas sexuales que sostenían con los clientes (por ejemplo muchas excluían los besos o el sexo anal). Una de ellas me decía que con sus "amigos" se "sentía bien" y me explicaba: "Que me sienta bien es que me sienta cómoda, cómoda y que me pueda liberar, dejarle hacer cosas que quizás con alguien que recién conozco no se las dejo hacer" (Yamila, 27 años, ES). Los vínculos con clientes-amigos permiten hacer excepciones a reglas y límites, en parte porque esta "amistad" puede resituar la relación no sólo excediendo el marco sexual, sino incluso ubicándola en un lugar diferente respecto del canon laboral.

Sí, es como que o te llaman...o te mandan un mensaje. Algunas veces te traen regalos $y$ es como que vos te sentís...eh...no te sentís tanto como que... eh... que estás laburando totalmente. Pero esa clase de personas no son la mayoría. Son pocos. Son contados. O por ahí de repente se acuerdan la fecha de tu cumpleaños. O por el día de la madre o por el día del amigo. Entonces vos, a esas personas vos les tomás... eh... de otra forma, otro trato (Irene, 49 años, CLL).

La connotación de amistad puede llevar a sentir que "no estás laburando totalmente", pero no implica estar enamorada ni dejar de cobrar. En un sentido similar al que atribuyen algunos estudios sobre "turismo sexual" (Cabezas, 2004; Piscitelli 2007, 2011), las relaciones con los clientes llamados "amigos" encuentran un lugar liminal entre el trabajo y el amor, donde el afecto no disputa el lugar de los ingresos - como sí sucedía con los enamoramientos que vimos más arriba. A la vez, este espacio liminal desarticula la rigidez de la identidad estigmatizada asociada a la prostitución y el afecto de los clientes-amigos interpela diluyendo el estereotipo de prostituta con las identidades de 
"amiga", "mujer" o "madre", socialmente más valoradas. No obstante, a diferencia de las relaciones en el marco del turismo sexual donde algunas mujeres entablaban "romances" con los turistas extranjeros y buscan evitar el cobro directo por el sexo, las entrevistadas se podían dejar llamar "novia" por los clientesamigos pero eso no excluía el cobro de la "salida".

Elizabeth Bernstein (2007) señala la aparición una modalidad de servicios sexuales que pueden entenderse como un lazo de "amor temporario" - lo que ella denomina bounded authenticity, que diferencia entre el servicio de girlfriend experience (que en la jerga local se llama "onda novia") y la mera descarga sexual, más propia del sexo comercial callejero. ${ }^{9}$ De las mujeres que entrevisté los vínculos con clientes-amigos eran más frecuentes entre las escorts, quienes al cobrar tarifas mucho más elevadas no necesitan tener tantos clientes. Las escorts y los clientes-amigos también sostienen espacios de sociabilidad (reales $y$ virtuales ${ }^{10}$ ) que exceden lo laboral. Ellas dicen disfrutar estos

9 Según Bernstein (2007:171) esto es parte de un paradigma nuevo de sexo comercial que, aunque tiene precursores históricos - cortesanas europeas, geishas japonesas o devadasis indias, representa una transformación respecto del modelo moderno de prostitución. También otros estudios señalan la presencia de performances parecidas en Copacabana, Brasil (Silva; Blanchette, 2005). Resulta difícil saber hasta qué punto este paradigma de "sexo comercial postindustrial" como opuesto al modelo moderno se adapta a las configuraciones de los mercados sexuales argentinos (en un sentido similar apuntan las diferencias que plantea Piscitelli para comprender las especificidades del llamado "tercer mundo", 2011). Claramente esto demanda una investigación con una mayor extensión. Haber logrado una cuota menor de entrevistas a escorts limita las posibilidades analíticas en este sentido.

${ }^{10}$ Además de los relatos de las entrevistas, las interacciones entre clientes y escorts en los foros de Internet - aunque no excluyen los conflictos - también muestran una sociabilidad amistosa. Esta sociabilidad virtual no es anónima, todos/as están registradas/os como "usuarios/as", lo que permite recrear identidades y construye cierto sentido de "comunidad virtual" - lejana del anonimato total de "la prostitución"- que, claro, tampoco está exenta de intereses comerciales. El desarrollo de las formas de identificaciones y sociabilidad en estos foros amerita una investigación aparte para profundizar en el análisis. Sin embargo una observación superficial permite notar que el sistema de foro con usuarios registrados y con "rangos de confianza", supone un 
encuentros en fiestas, salidas grupales o cenas y también aquí pueden obtener nuevos contactos. Por ejemplo, podían reunirse con clientes por fuera del trabajo en un ámbito recreativo y esto les generaba muchos contactos con otros varones que pueden ser luego clientes - tal como sucede en otras reuniones extra-laborales donde se tejen redes de contactos. Este tipo de vínculos son usuales entre las escorts, quienes aplican más habitualmente la denominación de "amigo" para sus clientes y valorizan su capital social a partir de los contactos que reúnen.

Tal como aclaraba Irene más arriba, muchas entrevistadas destacaron que los clientes-amigos no eran la mayor parte de los clientes. Sin embargo, todas mencionaron tener algunos vínculos de este tipo, incluso aquellas que remarcaban ser "frías" con los clientes - como Mirta que sonrió al recordar a un par de clientes frecuentes y admitió extrañarlos cuando no venían a verla. Entablar este tipo de lazos no depende sólo de la modalidad o estrato de sexo comercial, sino que se liga a la duración del vínculo y también supone aprender a controlar las emociones para sostener una distancia entre los clientes-amigos y los sentimientos amorosos románticos.

El cliente por ahí ve carita nueva, y por ahí salió cinco años con vos y por ahí de repente ve una chica nueva y empezó a salir y le empezó a gustar, empezó a salir y te dejo a vos y salió con otra (Mirta, 39 años, CLL)

Resulta que un día me bajo yo a verlo a mi novio y $\mathrm{mi}$ novio se enganchó a otra y se la llevó, supuestamente él era mi amor, viste. Yo te puedo asegurar que ahí cayó mi corazoncito y se rompió toditito ahí, digo "Nunca más", dije, "Ya está" (Doris).

Mirta señalaba la necesidad de no olvidar la faceta comercial y Doris muestra cómo pasar a ver como "novio" a un clienteamigo puede ser afectivamente riesgoso. Las relaciones con

contexto distinto del más anónimo de las salas de chat (ver por ejemplo el artículo de Martín Boy en Pecheny, Figari y Jones, 2008). 
clientes-amigos implican algo más que un vínculo comercial, en términos de afectos y de compartir intimidad, pero no por ello suponen exclusividad - lo que puede resultar confuso cuando se lo llama "novio". Doris pasó (¿sin notarlo?) de un vínculo afectuoso a uno amoroso romántico con un cliente-amigo. La decepción al ver salir a su "novio" con otra compañera transformó radicalmente su percepción del vínculo (y de los vínculos con los clientes en general) pues su enamoramiento había eclipsado el aspecto comercial del vínculo. El corrimiento abrupto del tono romántico y exclusivo del vínculo ("supuestamente era mi amor") la situó, según sus palabras, claramente en el lugar de prostituta ("ahí me desperté y dije: "yo soy una prostituta"). En el caso de Doris, que se autodefine como "una novelera de primera", no fue recibir el dinero de los clientes, sino el desengaño amoroso lo que la (re)posicionó-expulsó: "soy una prostituta más, soy la que siempre la gente discrimina", una abyecta del romanticismo.

El afecto en los vínculos de sexo comercial puede tornarse difícil de manejar cuando se tiñe con una demanda amorosa de exclusividad. ${ }^{11}$ Entre las escorts que pude entrevistar había un manejo más cuidadoso de este tipo de vínculos, probablemente porque eran más frecuentes en este estrato y porque ejercían un mayor control de sus emociones - sólo Carina, la única escort mayor de 30 años, relató haberse enamorado de un cliente. El cobro de la tarifa establecida por la "salida" sirve como anclaje de la relación comercial. Aunque luego pudieran entablar amistades y trabajar con tiempos y prácticas flexibles, este cobro marcaba que no había un vínculo romántico. La tarifa - que fija un precio en dinero para un servicio con determinadas prácticas sexuales en un determinado lapso de tiempo, siempre reinscribía el vínculo en el terreno comercial. ¿Cómo interpretar entonces los bienes o el dinero extra-tarifario?

\footnotetext{
${ }^{11} \mathrm{He}$ analizado en otro artículo el papel que desempeña el trabajo emocional entre las mujeres que hacen sexo comercial, tanto para exhibir como para ocultar estados emocionales (ver Morcillo, 2014).
} 
Los "regalos", las "ayudas". Más allá (y más acá) de la lógica comercial

Muchas entrevistadas contaban que algunos clientes les regalaban dinero o bienes de diverso tipo (desde perfumes y ropa, hasta mercadería de almacén y pañales). Tanto los regalos como otros tipos de flujos de dinero y bienes escapan a la lógica comercial en su sentido más estrecho (el pago compensatorio por la "salida"). Veamos, entonces, las distintas formas de circulación de dinero o bienes para comprender sus significados en los vínculos.

Un tipo de tráfico económico muy común son las "ayudas", que pueden ser en dinero y/o en bienes o servicios. Por ejemplo, una forma de circulación de dinero extra-tarifario aparece como préstamos que no se reintegran a los clientes. Algunas entrevistadas contaban que, en momentos de necesidad económica, clientes-amigos de larga data les habían prestado dinero pero aclarando que no tenían obligación de devolverlo. ${ }^{12}$ Las "ayudas" también pueden incluir llevar alimentos o abrigo cuando las mujeres están detenidas - como hacía un "enamorado" que llevaba botellas de agua al calabozo para que Susy soportara el agobiante calor de verano. Otra forma de las "ayudas" son las colaboraciones con los gastos de manutención de los hijos/as. Beatriz sostuvo durante muchos años un vínculo con un cliente-amigo, quien la ayudó durante todo su embarazo y el nacimiento de su hija, y me explicaba: "Esas personas te hacen sentir, no un objeto, te hacen sentir persona, te valoran". El elevado valor que tiene la maternidad para estas mujeres hace que este tipo de ayudas sean muy apreciadas y despierten un afecto especial. Algunos de estos gestos ponen en cuestión los estereotipos de los clientes como hombres violentos que sólo buscan ejercer dominación sobre las mujeres. Juana contrastaba las atenciones y ayudas de sus clientes con la desafección del

\footnotetext{
${ }^{12}$ Este préstamo, si bien podía crear alguna otra obligación, esta permanecía difusa. Esto supone una diferencia respecto a las deudas que se contraen y que generan un compromiso monetario, lo que la literatura anglosajona llama debt bondage.
} 
padre de su hija, Úrsula relataba algo similar respecto al abandono de su familia:

No, [el padre] ni vio nacer a mi hija, nada. Después desgraciadamente, en julio, la internaron a mi hija, yo estaba trabajando en la calle, la internaron a mi hija en el hospital Rawson y agarré yo y me vine, le dije a la Hilda, a la Marcela [otras colegas], le digo: "Mirá, voy a volver a la parada". A mi hija le empezaron a pedir cosas y yo plata no tenía. Gracias a dios me habían salido unos buenos clientes que me ayudaron un montón, te digo, con plata, con pañales, inclusive la iban a ver todos ellos a mi hija (Juana, 36 años, CB).

Yo he tenido clientes de años acá... Pero... más que nada he ganado un poco de amistad con todos estos. Porque yo por ahí tengo algunos problemas y ellos... están... Y capaz que mi familia no... ¿̇Me entendés? (Úrsula, 42 años, CLL).

Las "ayudas" parecen situar las relaciones con estos clientesamigos más allá del mundo del sexo comercial, y aparejadas con los vínculos familiares. En trabajos recientes se viene analizando cómo relaciones surgidas en el mercado sexual pueden reinterpretarse en la clave de parentesco (Olivar, 2013; Piscitelli, et al., 2011). Ciertamente la lógica que da sentido a las "ayudas" escapa a una lectura mercantil en sentido estricto y complica su interpretación en términos de las formas de intercambios más comunes. Las "ayudas" comprendidas como una forma de solidaridad se distancian del pago como compensación y (en menor grado) de los regalos. No llegan a ser un "derecho", algo exigible, pero sí se puede pedir una ayuda, lo cual sostiene cierta relación de desigualdad de poder, pero disminuye el componente arbitrario de los regalos.

Piscitelli (2011:13) plantea que las "ayudas" pueden comprenderse, en un sentido amplio, como "intercambios, generalmente asimétricos, que implican dinero y/o otros beneficios y tienden a crear obligaciones $y$, con frecuencia, afectos". ${ }^{13}$ Así,

${ }^{13}$ Todas las traducciones son propias. 
estos intercambios que representan las ayudas, permiten hacer circular otros sentidos en las relaciones iniciadas en el mercado sexual.

Si el "programa" ["salida" en la jerga local] evoca un contrato de servicios, la ayuda, inserta en una tradición de intercambios jerárquicos, remite a nociones de amparo, cuidado $y$ afecto, que se expresan en términos de contribución para la supervivencia económica y para el consumo (Piscitelli, 2011:550).

Es clave tomar en cuenta que las ayudas no implican la carga de estigma del que tiene el pago por la salida. Aunque Piscitelli aclara que no debe pensarse en términos de una oposición dicotómica entre el pago de la "salida" (programa) y las "ayudas", en cada una de estas formas de circulación de dinero o bienes hay sentidos y lazos diferentes.

Un punto significativo de las relaciones con los clientesamigos es que las mujeres no dejaban de cobrar las "salidas" aun cuando recibieran ayudas. Estas relaciones comerciales, si bien evitaban el involucramiento romántico, no implicaban la exclusión de la amistad. En estos vínculos, el cobro de la tarifa por la "salida" es una forma de evitar confusiones, pues "la gente generalmente confunde muchas cosas, confunde la amistad con...temas sentimentales" (Abril, 25 años, ES). Así, aunque pudiera parecer paradójico, mantener el aspecto más claramente comercial - cobrar la "salida"-, era el que permitía sostener los vínculos afectivos amistosos que se expresaban en las "ayudas".

Además de las "ayudas", Doris me explicaba que la tarifa pactada no es todo lo que se recibe: "No es que yo digo, arreglamos un precio y, bueno, por esto va todo. ¿Me entendés? Si me querés hacer un regalito, bienvenido sea". Estos "regalitos" o extras del servicio son la modalidad más cercana al pago compensatorio estandarizado de la tarifa por la "salida", pues sólo agregan un plus al precio convenido. Por fuera del valor que pone el mercado sexual - y por fuera de los porcentajes que retienen los 
proxenetas -, este plus se entrega según el criterio del cliente, es decir que no es algo que se pueda exigir. La intención de los clientes que otorgan ese extra puede ser diversa: expresar afecto, crear un lazo especial, mejorar la calidad del servicio, mostrarse como generosos $\mathrm{y} / \mathrm{o}$ poderosos, o varias de estas juntas (Bernstein, 2001). Aquí la intercambiabilidad del dinero hacía que las entrevistadas recibieran estos dineros sin preocuparse demasiado por cuáles sean esas intenciones. Pero, también mencionaban que con frecuencia recibían regalos que no consistían en dinero:

Cuando viajan... apenas llegan, por ahí ni están... Vienen y es para dejarme el regalo que me trajeron de recuerdo de donde anduvieron. Algo para mí, algo para mi nene y se van... y después cuando tienen tiempo y están tranquilos, vuelven... (Luli).

En estos regalos no monetarios desaparece el símbolo del dinero. Según Georg Simmel (1993) el carácter impersonal del dinero sería lo que hace socialmente degradante al intercambio de la prostitución. En la lógica de los intercambios afectivos que plantea Simmel, la degradación de las prostitutas se produce al intercambiar lo más personal (el sexo) por lo menos personal (el dinero) reduciéndolas a una cifra monetaria. Venimos viendo que en las relaciones de sexo comercial hay muchos matices que pueden hacer más complejo este esquema un tanto simplista de Simmel. No obstante, sin negar la versatilidad de significados que puede asumir el dinero en los distintos tipos de pagos, algo de la óptica simmeliana - por contraste - nos permite comprender el papel de los regalos. Cuando estos no son dinero, gratifican (o incomodan) ya no tanto por la forma en que se entregan, sino porque su contenido aludiría a una singularidad (o no). Según la alusión que hagan, colaboran en una resignificación o complejización de la identidad de estas mujeres. Si las ayudas consistían en algo que las mujeres necesitaban y representaban sentidos compartidos, en el caso de los regalos no monetarios las significaciones pueden ser más complejas en términos de cómo 
sitúan a las mujeres. Así, Inés percibía con sentimientos ambivalentes los obsequios que recibía de un cliente:

Encima que [un cliente] te pague todo el día, como si fuese que, yo estaba... trabajando parada en una esquina $y$, encima que te compre ropa, te compre sandalias, que te regale una cartera... eh... te... ¿Cómo se dice? Te dé plata para la peluquería, yo me sentía bien. Me hacía sentir bien. Me hacía sentir importante. No sé... Pero él también estaba creando una mina ${ }^{14}$, porque yo no era esa, era la que él quería... que me vista así ¿Me entendés? Y que esté al lado de él así vestida, como él quería (Inés, 24 años, CLL).

Aunque Inés se "sentía bien" al recibir estos obsequios, su experiencia revela que la personalización de los regalos puede ser también una forma en que los clientes "fabrican", de una forma más unilateral, una imagen de la mujer y el tipo de vínculo que buscan. En este caso, el valor permanece ambiguo pues la singularización que operaban estos regalos no apuntaba a las características que Inés percibía como propias. La ambivalencia de los sentimientos de Inés, elogiada, revalorizada y a la vez desplazada de lo que ella percibía como su forma de ser, muestra lo complejo de los significados que asumen los regalos no monetarios. La interpelación más singularizante de los regalos pone de relieve ambivalencias de las identificaciones de estas mujeres. Y no es casual que los regalos que eran siempre bienvenidos fueran los obsequios para sus hijos/as, puesto que aludían a su preciada identidad de madres.

Otras investigaciones señalan que a veces los regalos no monetarios pueden incomodar, pues implican un afecto que transgrede los términos del intercambio comercial y no otorgan la "libertad" que supone el dinero al poder ser cambiado por cualquier otra cosa (Russo, 2008). En las entrevistas que realicé, estos valores de "libertad" asociados al dinero aparecían ligados al consumo sobre todo cuando las mujeres apenas comenzaban a

14 "Mina" es usado en el lunfardo de Argentina como sinónimo de "mujer". 
hacer sexo comercial. Pero luego eran más generalmente expresados como "posibilidad" (de salir de la pobreza o poder estudiar) y aparecían casi siempre mediados por el vínculo maternal (poder mantener, educar, dar mejor calidad de vida a los/as hijos/as). Por ello mismo, cuando apuntaban a los/os hijos/as, el valor simbólico de la maternidad compensaba el escaso valor de cambio de los regalos no monetarios, pues expresaban una identificación positiva y ampliamente compartida.

\section{Sin tarifa. "Viejos" amigos o amantes-renta.}

En otros casos, las mujeres entablaban relaciones con algunos clientes-amigos donde los pagos abandonaban completamente la forma tarifada. En estas relaciones el flujo monetario deja de estar ligado a las contraprestaciones sexuales, tal como sucede con el modelo de los sugar daddies. Para María estas relaciones significaban un ingreso fundamental y se jactaba de su logro.

María: No creo que, que todos los viejos mantengan a todas las putas o a todas las minas porque sí. Noooo...

S: ¿Y por qué creés que a vos te pasa eso?

María: Porque tengo buena relación, somos amigos. Yo, de mis clientes, hay algunos que rescato que soy amiga, no son clientes para mí, somos amigos, entonces ¿Por qué? Por años de relación, por escuchar un montón de cosas, a veces yo sé cosas que no les cuentan a los amigos, que me las cuentan a mí, cosas de su pareja, de sus hijos ¿Entendés? Entonces creás un vínculo de amistad y cuando tenés un vínculo de amistad, una persona grande, con una persona más joven, como yo ¿Entendés? Y ves que cada vez que yo he necesitado estar, y la otra persona necesitaba cualquier cosa mía yo estoy, entonces uno llega a tener cariño con esa persona. Yo te digo, a Fran no lo soporto porque es un 'seca-mente' [molesto], pero [...] viene y me tira cien pesos por la ventana, le pedí mil seiscientos y me dejó cien el lunes, pero no tiene obligación conmigo, es lo que me dicen: "¿es tu macho?" No, no es mi macho, no tiene 
obligación pero ¿Por qué lo hace? Porque me quiere, un afecto tiene conmigo, sabe que no se me puede dejar sola. Es igual al Serafín, yo le digo, viste, que por lo menos por prestarles el oído que me dejen plata, porque he sido amiga de ellos un montón de años, entonces que me paguen por haber sido amiga, que me indemnicen los oídos de última (risa) (María, 31 años, $\mathrm{PV}^{15}$ ).

Según María, para estos "viejos" amigos ella es una "novia". Los aportes económicos habituales - sobre todo de Serafín formaban parte de los ingresos estables de María. Ellos fueron clientes de sexo comercial, y aunque seguían teniendo relaciones sexuales hay también una relación que ella describe como afecto. María sabe que no tienen obligación de mantenerla porque ninguno es "su macho" y a la vez entiende que "prestar la oreja" también constituye un servicio que debe ser remunerado. Pero estos pagos son más difusos y no responden a una tarifa fija por cada servicio. María puede pedir estos pagos cuando le hacen falta, como hacía con Fran, o simplemente contar con que recibirá esos dineros como le sucedía con Serafín ${ }^{16}$ : "él, por ejemplo, no

${ }^{15}$ Esta entrevistada había comenzado trabajando en un "privado", sin embargo en los últimos años había conseguido montar su propia "agencia de chicas", sin abandonar ella misma los encuentros con algunos viejos clientes. El caso de María puede entenderse como uno de los patrones de proxenetismo que O'Connell Davidson (1998) llama "proxenetismo de emprendedor/a" (entrepreneur pimping). En esta modalidad de proxenetismo es frecuente hallar a quienes han hecho o aún hacen sexo comercial, tal como María.

${ }^{16}$ Según María, el más querido de sus "amigos" era Serafín y sus aportes eran tan importantes como incondicionales: "El prioriza a su familia, que no todos los hombres priorizan a su familia, él sí. [...] Tiene 'enconche', como todo hombre, porque sale con pendejas más jóvenes, pero nunca les ha hecho faltar nada, la mujer tiene, él, el sueldo de él depositado en la cuenta de la mujer, todo, todo para la familia. Y, obviamente, todos los rescates que se hace va y los reparte, porque tiene un montón de novias. Por eso yo lo quiero, porque el chabón prioriza a su familia y después todo lo demás. Y así no me deja nunca y aunque no estemos, no nos vemos nunca, me llama por teléfono y yo le pido plata, y si no puede venir él, me manda a alguien, así. Es buen amigo (Ríe) Porque económicamente no me deja [...] se merece que lo quiera". Siguiendo el relato de María, podríamos preguntarnos hasta dónde se extiende la familia de Serafín. 
hace falta que yo le diga: 'Mirá, Serafín, no tengo plata', él viene para verme y me golpea la puerta y me dice: "¿Cómo anda? ¿Bien? Tome un regalito' [haciendo el gesto de entregar dinero]" (María). A diferencia de los "regalitos" como extra que mencionaba Doris más arriba, y de los regalos no monetarios, estos son pagos monetarios similares a las "ayudas" $y$ relativamente estables más allá del "servicio".

Claudia Fonseca (1996) señala que entre las prostitutas de Porto Alegre el cliente favorito es el "viejo":

Un cliente que se convierte en fijo (freguês) proporcionando, además del pago regular, una amplia gama de regalos. [...] El viejo (velho) no se confunde con el marido. Es un tipo de otario que alimenta la ilusión de ser único o al menos privilegiado en lo que respecta a los afectos de la mujer [cursivas en el original] (Fonseca, 1996:24).

Los "viejos amigos" de María, se asemejan a este modelo del velho - que según Fonseca no es exclusivo de las prostitutas. Sin embargo, la especificidad de las relaciones que entablaban tanto María como otras entrevistadas con algunos clientes radica en la eliminación del pago regular que menciona Fonseca. Al desaparecer el pago por la "salida", todo el dinero y los bienes circulan bajo la forma de pago que, al ser el único modo de intercambio, adquieren un sentido de mayor obligación que las "ayudas" que otorgan los clientes-amigos. Por ello, estos pagos no son estrictamente una compensación ni un regalo, sino algo más cercano a lo que Zelizer categoriza como un "derecho", pues aunque no hay una transacción explícita, las mujeres pueden sentir que merecen estos dineros o bienes. ${ }^{17}$ Aun estando en una posición estructuralmente subordinada, ellas pueden lograr capitalizar su ascendente sexo-afectivo sobre estos varones, y algunas decían controlarlos y mostraban cierto desprecio.

${ }^{17}$ Tal como plantea Zelizer (2008) que sucedió con el "bono de navidad" devenido un derecho de los empleados. 
A mí Fran no me gusta porque es un gordo espantoso, pero es porque es un gordo espantoso, encima pesado, si fuera un gordo agradable... tiene una verga [expresión de desagrado], si fuera agradable bueno, pero es un gordo espantoso, pesado [...] lo hago que me chupe la concha cuarenta minutos, me lo garcho en cuatro minutos y me voy a bañar y voy a hacer todo lo demás en los quince minutos, una hora clavadita, y si puedo menos (María).

Aunque las mujeres suelen burlarse de los velhos especialmente frente a otras mujeres - pueden sostener lazos de afecto y respeto (Fonseca, 1996; Piscitelli, 2011). María mantenía medido el tiempo de los encuentros sexuales con Fran - uno de los parámetros que delimitan la relación de sexo comercial -, pero a veces se quejaba de las eyaculaciones precoces de Serafín y hubiera querido que "durara más", "soportaba" a uno, "quería" al otro. A pesar de estas diferencias, con ellos ha entablado vínculos extendidos durante largos años y a ambos los concebía como sus "viejos amigos". En este tipo de relaciones de larga duración y que se salen de los estereotipos de la prostitución, también la aparición de sentimientos románticos en los clientes puede introducir una variante.

S: ¿Y cómo fue que empezaste a eso, a relacionarte con él de otra forma?

Beatriz: No lo quería yo, yo no lo quería, ni lo amaba, ni lo quería, nos pusimos de novios, todo porque él me daba mucha plata.

S: Ah, ¿Pero siempre te siguió pagando?

Beatriz: A mí ya no me pagaba, ya me daba todo.

S: ¿Cómo te daba todo?

Beatriz: Todo, plata, todo lo que yo le pedía me daba, porque él tenía esperanza de que yo sea la mujer definitiva de él, apostó eso y bueno, no, no, no era así porque yo no lo quería, yo lo quería por lo que él me daba, ya no me pagaba, ya me daba lo que yo le pedía.

S: Ahá, pero ¿no te pagaba cada vez que tenían relaciones? 
Beatriz: Noooo, a mí me traía: "Yo hoy necesito tanto. Mañana tanto" y él venía: "Tomá, tomá y tomá" y todos los días tomá.

Además de los lazos de "amistad" como clave de las variaciones de los vínculos comerciales, también las pretensiones amorosas de los clientes pueden hacer que cambie el vínculo. Más arriba he descripto las transformaciones que aparecían cuando los sentimientos románticos eran mutuos, ahora me refiero a los casos donde estos no afectaban a las mujeres. En estas relaciones los clientes, devenidos lo que llamaré amantes-renta ${ }^{18}$ : dejaban de pagar por la "salida", se mostraban como enamorados y planteaban el vínculo en un supuesto horizonte de pareja, aunque no había una correspondencia en los sentimientos de parte de las mujeres.

La ilusión de estos amantes, quienes creen o aspiran a ser únicos, llevará a que las mujeres desplieguen tácticas para sostener esta fantasía y así obtener mayores beneficios. Aquí también el pago deja de ser tarifado, el dinero se entrega desde la confluencia de los deseos amorosos de los amantes y su pretensión de exclusividad sexual. En estos casos, que no eran frecuentes entre las escorts ni entre las mujeres más jóvenes, las entrevistadas se empeñaban en revelar una mirada más interesada en la faceta económica y desligada del afecto.

La pretensión de tener un velho que ajude aparece como legítima entre las mujeres de clases populares en Brasil, y es un objetivo que puede estructurar las carreras de las prostitutas (Blanchette; Silva, 2009; Fonseca, 1996). También en Argentina en los '80, Estela Soto encontró entre las prostitutas la expectativa de que algún cliente les provea protección y sustento económico para "dejar la calle". Según la autora, en general estas relaciones no

${ }^{18}$ Uso esta denominación pues varias veces las mujeres apelaban a la comparación con las relaciones de amantes para describir estos vínculos. También Piscitelli (2011) menciona la categoría de "amantes estables" para relaciones similares a las sostenidas con los velhos pero sin asimetrías etarias y de clase tan marcadas. 
duraban más que algunos meses, salvo cuando las mujeres aceptan sostener una relación paralela con hombres que tienen otra familia y muestran una actitud de renuncia "en beneficio del otro grupo familiar" (Soto, 1988:73). Este "punto fijo" (un único cliente que mantiene a las mujeres) se asemeja a lo que llamo amante-renta. Sin embargo, en las entrevistas que realicé en general no se mencionaba al "otro grupo familiar", las mujeres asumían una posición menos pasiva y más desconfiada hacia los clientes "enamorados". La manipulación de estos vínculos siempre era relatada como algo consciente. La dramatización de emociones buscaba aprovechar el dinero, los bienes o inmuebles que proporcionaban los amantes-renta.

En dos años un cliente me daba todos los días un cheque de 100 pesos y no quería que estuviera en la esquina, pero yo me quedaba igual por las ganas que tenía de trabajar... (Mabel, 45 años, CLL).

Mabel engañaba a un cliente que le pedía exclusividad pues no estaba dispuesta a abandonar "la esquina" y resignar su fuente de ingresos. Varias entrevistadas, especialmente las más jóvenes, valoraban más la independencia que les daba tener varios clientes y sostener su trabajo, en vez de ser mantenida por un amanterenta y circunscribirse a ese vínculo. La pretensión de exclusividad de los amantes-renta supone perder cierta cuota de independencia, y además requiere de las mujeres un trabajo emocional intenso y cotidiano para sostener la ilusión de aquellos. Por ello, algunas dijeron no soportar estas presiones, sobre todo aquellas que tenían una mirada más romántica y desinteresada del amor. Al referirse a los amantes-renta trazaban paralelos con "algunos matrimonios":

La ama de casa que aguanta al marido. Aunque no lo quiere, no siente nada con él... porque le deja el sueldo... Pero está bien visto, y ella está sufriendo horrores. ¿Qué diferencia hay ahí? ¿Vos le ves la diferencia? No hay diferencia. La gente no se separa y 
aguanta al tipo lo que sea. "iChe, traeme la comida!" Y la mujer viene con la comidita [...] No todo es amor (Risa leve) (Susy, 49 años, CLL).

En el imaginario romántico, el contexto amoroso del matrimonio anularía cualquier mirada especuladora de los cónyuges que pudieran estar buscando obtener algún beneficio. Cuando este contexto $y$ las acciones supuestamente desinteresadas son puestas en cuestión la concepción de la relación cambia y no parece tan lejana a aquella del sexo comercial. Jean Duncombe y Dennis Marsden (1996) estudiaron las parejas heterosexuales de larga duración y resaltan el papel del "trabajo sexual" en su sostenimiento. El "trabajo sexual" es definido, en este caso, como los esfuerzos que se llevan a cabo para tener sexo considerado satisfactorio. Según Duncombe y Marsden son mayormente las mujeres quienes realizan este trabajo sexual - los hombres sólo lo harían al principio de la relación, antes del matrimonio -, y el sentido del contrato matrimonial se transforma cuando este trabajo desaparece.

Cuando las relaciones son despojadas de los apuntalamientos del trabajo sexual [...] las diferentes dimensiones de poder interpersonal emergen más severamente y el sexo asume un valor de cambio, ahora regulado por negociaciones verbales o corporales más explícitas que los anteriores "contratos" (Saunders, citada en Duncombe y Marsden, 1996:235).

Para Susy - quien daba un gran valor a la conquista romántica y admitía ser comprada sólo con "flores y bombones" 19

\footnotetext{
${ }^{19}$ Susy sostenía que a diferencia de los varones "las mujeres funcionamos por la conquista [...] tiene que ser caballero, amable... Qué sé yo, todo lo que vemos las mujeres (Risa leve). Parece una tontera, pero... pero funcionamos así. ¿Por qué a las mujeres les regalan bombones, flores, de todo...? Porque a nosotras nos compran así. Nos tienen que conquistar". En estas expresiones la materialidad del dinero se contrasta con el carácter simbólico que tienen las "flores y bombones". Para varias entrevistadas la adherencia al discurso del amor romántico en sus
} 
- el paralelo entre los matrimonios interesados, sin amor, y los intercambios del sexo comercial se construye recortándose contra el ideal de amor romántico. Para ella, como para otras entrevistadas que se identificaban como románticas (generalmente las de mayor edad), el contraste con el "amor verdadero" monogámico y desinteresado - acababa igualando las relaciones con los distintos clientes ("aunque algunos crean que somos amigos"). A diferencia de aquellas más alejadas de los ideales románticos - que podían combinar afecto e interés, las que entablaban vínculos con amantes-renta lo hacían desde el desdoblamiento entre cinismo y romanticismo.

\section{Reflexiones finales}

Allí donde las narrativas dominantes subsumen todos los sentidos del sexo pago en dinero como una "degradación de la mujer", es necesario indagar si son posibles (y cómo) otras formas de vínculos en el sexo comercial. A partir de los tránsitos y las figuras intersticiales analizadas en este artículo podemos reflexionar sobre los diversos significados que emergen en el mercado sexual y que se desplazan del estereotipo asociado a la prostitución. La cuestión del pago tarifado y monetario contribuye a delinear las relaciones, pero no les da un sentido por sí sola, también intervienen el manejo del tiempo en los encuentros, las formas de domesticidad o comensalidad, los regalos nomonetarios, la duración del vínculo a lo largo del tiempo y la presencia o no de una pretensión de exclusividad. Todos estos elementos se conjugan para trazar las relaciones con clientes, clientes-amigos y "viejos" o amantes-renta. Al tomar en cuenta todo este esquema, vemos que el dinero puede adquirir diferentes significados en diversas relaciones económico-sexuales. Si tomamos en cuenta las distinciones que propone Zelizer (regalo, compensación y derecho) como formas de marcar relaciones, 
podemos leer los desplazamientos en los pagos como corrimientos respecto de las concepciones más tradicionales o estereotípicas (matrimonio / prostitución). Según los contextos y los vínculos, el que en las primeras experiencias de sexo comercial pudo haber sido "dinero sucio" de un desconocido que paga por sexo, también puede implicar un gesto cariñoso ( $\mathrm{y} / \mathrm{o}$ de superioridad) de un cliente-amigo, una forma de "ayuda" hacia algún miembro de la familia, o el derecho que debía pagar un amante-renta.

La comprensión de los distintos vínculos sexualeseconómico-afectivos que emergen en el contexto del sexo comercial requiere complejizar una visión binaria que opone matrimonio-amor por un lado y prostitución-dinero por el otro. En las historias de algunas entrevistadas la aparición del afecto y luego el amor llevaba a la paulatina desaparición del cobro por la "salida". Pero este cobro también desaparecía con el supuesto amor y exclusividad sexual que encubrían el interés económico de los vínculos con amantes-renta. En otras oportunidades se continuaba cobrando y los vínculos se afianzaban en un lugar intersticial de "amistad". Las relaciones con clientes-amigos consolidan afectos $\mathrm{y}$, aunque no se pretendan desinteresadas (como quiere el discurso romántico), trazan vínculos de solidaridad y aprecio dentro del terreno supuestamente impersonal del sexo comercial. Los obsequios y atenciones juegan un importante papel para personalizar estos vínculos, así también las "ayudas" que permiten ampliar el marco comercial más estrecho. En tanto estos intercambios incluyen muchas veces a los/as hijos/as reinscriben sutilmente los vínculos en una trama familiar $e$ hibridan las identificaciones superponiendo "prostituta" y "madre".

Los distintos lazos que hemos explorado en este artículo muestran que ni las fronteras ni las profundidades del sexo comercial pueden ser trazadas de forma definitiva y lo inscriben dentro de un continuo fluido de relaciones sexuales económicas más que como una excepción. $\mathrm{Si}$ bien los tránsitos de enamoramiento se desplazaban hacia el imaginario romántico, su paradero nunca era certero y la figura de los amantes-renta se 
asemejaba nuevamente a la del varón proveedor, pero ahora como parodia, fuera del marco matrimonial (con lo cual abre brechas para su cuestionamiento). En este sentido, el caso más significativo lo constituyen las relaciones con los clientes-amigos que operan un conjunto de desplazamientos respecto de juego de oposiciones (amor/prostitución) sin abandonar el terreno comercial. Por ejemplo - sólo por retomar un aspecto - si tradicionalmente la prostitución ha sido emplazada como una actividad pública, fuera del ámbito doméstico, los clientes-amigos ponen en cuestión esta distinción al entrar en los hogares y compartir intimidades sin cohabitar. En estas relaciones los lazos afectivos - que no excluyen el interés económico ni el sexo indican que los significados de los vínculos no tienen que ver exclusivamente con la compra-venta del sexo o su gratuidad, ni con la exclusividad sexual, sino también con otros aspectos como la duración del vínculo en el tiempo o el reconocimiento de las múltiples identificaciones. En este sentido, en las relaciones con clientes-amigos se ponen entre paréntesis los límites (sexualestemporales-espaciales) - usualmente puestos como barricadas que buscan trazar una frontera para proteger la intimidad del estigma. Por un lado, con el pago de la "salida" permanece claro el vínculo comercial, y a la vez los regalos y las "ayudas" - una forma de circulación de dinero que expresa el encabalgamiento sobre las distinciones - reducen el papel estigmatizante de la interpelación de prostituta/puta y habilitan el reconocimiento de otras identificaciones. El análisis de estas relaciones, aunque aparecen como marginales en términos cuantitativos, sirve también para romper con los esencialismos y comprender en su complejidad los diversos significados que puede asumir la compra-venta de sexo en distintos tipos de vínculos.

\section{Referencias bibliográficas}

Agustín, L. Lo no hablado: deseos, sentimientos y la búsqueda de pasárselo bien. In: OsBORNE, R. (ed.) Trabajador@s del sexo: derechos, migraciones y tráfico en el siglo XXI. Barcelona, Bellaterra, 2004, pp.181-192. 
Allen, B. et al. Afecto, besos y condones: el ABC de las prácticas sexuales de las trabajadoras sexuales de la Ciudad de México. Salud pública de México, 45, Supp 5, 2003, pp.594-607.

ARAÚJo, R. Prostituição: artes e manhas do ofício. Goiannia, Goiás, Editora da UCG, Cânone Editorial, 2006.

BARRY, K. Esclavitud sexual de la mujer. Barcelona, LaSal, 1988.

BERNSTEIN, E. The meaning of the purchase: Desire, demand and the commerce of sex. Ethnography 2, n 3, 2001, pp.389-420.

. Temporarily yours: intimacy, authenticity, and the commerce of sex. Chicago, University of Chicago Press, 2007.

Blanchette, T. G.; Silva, A. P. D. Amor um real por minuto. In: Diálogo Latino-Americano sobre Sexualidade e Geopolítica. Rio de Janeiro, 2009, pp.1-52.

BREWIS, J; LinSTEAD, S. "The Worst Thing is the Screwing" (1): Consumption and the Management of Identity in Sex Work. Gender, Work and Organization 7, n 2, 2000, pp.84-97.

CABEZAS, A. L. Between love and money: Sex, tourism, and citizenship in Cuba and the Dominican Republic. Signs 29, n 4, 2004, pp.9871015.

DAs BiagGio, N; VAllejOS, A; LenARDUZZI, Z; FIRPO, I. Las relaciones de género en la prostitución: construcción social de nuevas subjetividades. Universidad Nacional de Entre Ríos, 2008.

DUNCOMBE, J; MARSDEN, D. Whose Orgasm is this Anyway? Sex Work in Long-term Heterosexual Couple Relationships. In: WEEKS, J; Holland, J. Sexual cultures: Communities, values and intimacy. Basingstoke, Macmillan, 1996.

DWORKIN, A. Prostitution and male supremacy. Michigan Journal of Gender \& Law 1, n 1, 1993, pp.1-12.

FONSECA, C. A Dupla carreira da mulher prostituta. Revista Estudos feministas 4, $\mathrm{n}^{\circ}$ 1, 1996, pp.7-33.

FreITAS, R. S. D. Bordel, bordéis: negociando identidades. Petrópolis, Vozes, 1985. 
GASPAR, M. D. Garotas de programa: prostituição em Copacabana e identidade social. Rio de Janeiro, J. Zahar, 1985.

GIDDENS, A. La transformación de la intimidad. Madrid, Ediciones Cátedra, 1998.

Illouz, E. Romantic Love. In: Seidman, S; Fischer, N. y MEEKS, C. (eds.) Handbook of the New Sexuality Studies. New York, Taylor \& Francis, 2006, pp.41-48.

JEFFREYS, S. The industrial vagina: the political economy of the global sex trade. London; New York, Routledge, 2009.

KonG, T. What It Feels Like for a Whore: The Body Politics of Women Performing Erotic Labour in Hong Kong. Gender, Work and Organization 13, n 5, 2006, pp.409-434.

MaCKINNON, C. Prostitution and Civil Rights. Michigan Journal of Gender \& Law 1, 1993, pp.13-31.

. Sex equality. New York, Foundation Press, 2001.

MorCILLO, S. De cómo vender sexo y no morir en el intento. Fronteras encarnadas y tácticas de quienes trabajan en el mercado sexual. Revista Latinoamericana de Cuerpos Emociones y Sociedad 7, $\mathrm{n}^{\circ} 3$, 2011, pp.17-28.

. Entre sábanas y bambalinas. Ilusiones de intimidad, performances y regulación de emociones en mujeres que hacen sexo comercial en Argentina. Revista Ártemis 18, n² 2, 2014, pp.42-60.

O'Connell Davidson, J. Prostitution, power, and freedom. Ann Arbor, University of Michigan Press, 1998.

Olivar, J. M. N. Devir puta: politicas da prostituição na experiência de quatro mulheres militantes. Rio de Janeiro, EDUERJ, 2013.

PASINI, E. Limites simbólicos corporais na prostituição feminina. cadernos pagu (14), Campinas-SP, Núcleo de Estudos de GêneroPagu/Unicamp, 2000, pp.181-201.

PECHENY, M; FIGARI, C.; JONES, D. (eds.) Todo sexo es político: estudios sobre sexualidades en Argentina. Buenos Aires, Libros del Zorzal, 2008. 
PISCITElli, A. Shifting Boundaries: Sex and Money in the North-East of Brazil. Sexualities 10, n 4, 2007, pp.489-500.

. Industria del sexo y mercado matrimonial: La migración brasileña hacia Italia en el marco del "turismo sexual" internacional. In: HeRreRA, G.; RAMírez, J. América Latina migrante: Estado, familias, identidades. Quito, FLACSO, Sede Ecuador, 2008.

. Amor, apego e interesse: trocas sexuais, econômicas e afetivas em cenários transnacionais. In: PISCITELLI, A; OlIVEIRA ASSIS, G. D.; Olivar, J. M. N. (eds.) Gênero, sexo, amor e dinheiro: mobilidades transnacionais envolvendo o Brasil. Campinas-SP, Núcleo de Estudos de Gênero-Pagu/Unicamp, 2011, pp.537-582.

Piscitelli, A; Oliveira Assis, G. D.; Olivar, J. M. N. (eds.) Gênero, sexo, amor e dinheiro: mobilidades transnacionais envolvendo $o$ Brasil. Campinas-SP, Núcleo de Estudos de Gênero-Pagu/Unicamp, 2011.

Russo, G. H. A. Rodando a bolsinha: dinheiro e relações de prostituição.

In: Seminário Internacional Fazendo Gênero 8, UERN. Florianópolis/SC, 2008.

SANDERS, T. The Condom as Psychological Barrier: Female Sex Workers and Emotional Management. Feminism \& Psychology 12, n 4, 2002, pp.561-566.

. "It's Just Acting": Sex Workers' Strategies for Capitalizing on Sexuality. Gender, Work and Organization 12, no 4, 2005, pp.319342.

Silva, A. P. D.; Blanchette, T. "Nossa Senhora da Help": sexo, turismo e deslocamento transnacional em Copacabana. cadernos pagu (25), Campinas-SP, Núcleo de Estudos de Gênero-Pagu/Unicamp, 2005, pp.249-280.

Simmel, G. Filosofia do amor. São Paulo, Martins Fontes, 1993.

Soto, E. T. Mujer, condiciones de trabajo y salud laboral. Argentina, Ministerio de Salud y Acción Social, 1988.

TABET, P. La grande arnaque: sexualité des femmes et échange économico-sexuel. Paris, L'Harmattan, 2004. 
Zelizer, V. A. Pagos y lazos sociales. Crítica en desarrollo 2, 2008, pp.43-63.

. Dinheiro, poder e sexo. cadernos pagu (32), Campinas-SP, Núcleo de Estudos de Gênero-Pagu/Unicamp, 2009a, pp.135-157. . La negociación de la intimidad. México, D.F., Fondo de Cultura Económica, $2009 \mathrm{~b}$. 